\title{
A Study on the Equity Crowd Funding Operation Model and Its Risk Regulation in China
}

\author{
Xiuping $\mathrm{Li}^{1, \mathrm{a}}$ \\ ${ }^{1}$ Wuhan Donghu University, Wuhan City, Hubei province, 430071
}

\section{Keywords: Equity Crowd Funding; Operation Model; Risk Regulation; Internet Finance}

\begin{abstract}
With low operational risk, low transaction cost and high efficiency, Internet finance has become an important means to develop economy in recent years, which has injected new vitality into the financial development in the world. As a new type of Internet financing model, crowd funding breaks the scope of the traditional financing model, which expands financing channels for small and medium enterprises. At the same time, as a new financing tool, the risk of equity crowd funding cannot be ignored, including legal risks, model innovation risk and moral hazard. Based on the author's learning and practical experience, this paper first analyzed the connotation of equity crowd funding and then analyzed the equity crowd funding operation model in China. Finally, this paper put forward the countermeasures of risk regulation.
\end{abstract}

\section{Introduction}

Financial innovation promotes the development of the financial industry. With the development of the Internet, the new Internet financing ways gradually appear. As an innovative model, crowd funding first appeared in the United States. After the outbreak of the subprime mortgage crisis, the economic development in the US slows down. The emergence of crowd funding provides new financing channels to small and medium enterprises to a certain extent. It increase the employment rate and promotes the economic development. In the past two years, the crowd funding starts in China. The establishment of Demo Hour, Dreamore and other sites plays a driving role in promoting the development of Internet finance in China. It can be said that the burgeoning Internet financing has successfully attracted people's attention.

\section{The Connotation of Equity Crowd Funding}

Crowd funding is an English phrase, which refers to a behavior to support individuals or organizations who initiate the activity by raising funds from the mass. That is public financing or mass financing. In general, the platform on the network connects the fund raisers and investors. Funds raised from the mass are used to support a variety of activities, including disaster reconstruction, private fund raising, campaigning, business fund raising, art creation, free software, design inventions and scientific researches. Compared with the traditional finance, crowd funding lowers the threshold for participants. The time to obtain funds is relatively short and the transaction cost is low. To raise funds on the public crowd funding platform from the majority of investors also spreads the risk of a single investor, promotes the optimization of industrial structure and solves the financing problem for small and medium enterprises. At the same time, this financing way is open to the public and it has a promotion advantage to the financing enterprises. With the rapid development of the Internet today, as long as people have ideas and creation ability, they can initiate crowd funding projects regardless of their identity, status, occupation, age and gender. This characteristic of low threshold makes the crowd funding ways diverse. 


\section{Regulation Risks of Equity Crowd Funding in China}

Legal risk. One of the common problems in the development of equity crowd funding in all countries is its legitimacy. The Europe and the United States have a rapid response to the development of equity crowd funding. These countries promulgate bills timely to define its legal status clearly and introduce regulatory measures to promote its healthy development. However, China has not yet issued relevant laws and regulations on equity crowd funding. With the limitations of the Securities Law, Company Law and Criminal Law, the development space of equity crowd funding is greatly compressed and it operates in the gray area of the law. Equity crowd funding completes its financing process with two stages of "online + offline". The crowd funding platforms undertake responsibilities to check, display and publish online business projects. Platforms must ensure that the project is true, otherwise it will be an illegal fund raising project. When the venture project has raised the amount and investors do not exceed 50 people, the two sides conduct the process offline. The relevant investors set up a partnership company and sign a share transfer agreement with entrepreneurs according to the Company Law. Platforms do not participate in equity transfer and delivery. Although this avoids the illegal issuance of shares to a certain extend, it can not avoid the publicity of the project advertising. In strict accordance with the provisions of illegal public stock offerings in the Securities Law, to make the equity transfer information published on the Internet is one of legal requirements of information disclosure. Due to the free and easy environment in financial innovation in China, the definition of the legal nature of information disclosure is inconclusive, but its legal problems can not be underestimated.

Model innovation risk. As a kind of decentralized, point-to-point and innovative Internet financing model, there is a great difference in the subject between the equity crowd funding and the traditional equity transfer procedure. While the equity crowd funding improves the efficiency of financing, it also exposes many innovation-induced risks. First of all, the platform decides whether the project can finance on the platform according to the business plan submitted by the entrepreneur. Platforms will make a certain investigation on the project to help the approved project team to determine the issue price and the ratio of equity transfer. However, there is no access threshold and qualification requirements to the crowd funding platform. Therefore, its expertise and rationality are very questionable. Second, China's equity crowd funding adopts the operation model of " leading investment + following investment". The leaders mainly represent a large number of shareholders with small investment and they are responsible for the venture project management, supervision and notification of the operation in the company. As the management may be a very long process after the investment, whether the investment leader has always been dedicated to fulfill their duties before the capital withdrawal is still in doubt. Finally, the Internet economy has the characteristics of first-mover advantage, the Matthew effect and the "winner-take-all", so equity crowd funding platforms will be reshuffled after the cruel growth stage. The vast majority of small-scale crowd funding platforms will face mergers or bankruptcy. In this fluctuating period, equity crowd funding will cause a lot of risks. It is worrying whether they can protect the interests of investors.

Moral risk. In terms of the protection of investors' interests, there exists a greater moral hazard in crowd funding platforms and start-ups. The income of the crowd funding platforms is entirely dependent on start-up projects with successful financing. The vast majority of platforms charge $5 \%$ of the total project financing. Driven by economic interests, without qualified projects reference standards and regulatory constraints, platforms can easily lower the threshold of entrepreneurship projects subjectively and permit more projects into the platform to raise funds. At the same time, it cannot be excluded that the platform and financing enterprises conduct insider trading, connected transaction and even "self-financing". If the moral hazard on the platform cannot be effectively eliminated, it will lead to "The Market for Lemons", which 
may have a huge impact on the healthy development of equity crowd funding. In order to be favored by investors as much as possible and increase the success rate of fund raising and the corporate valuation, start-up enterprises will package the project overly and try to avoid the risk in the project. They will use some extremely optimistic, exaggerated and misleading publicity to attract investors. When the enterprise is successful in financing, with the pursuit of their benefit maximization and the exemption asylum of necessary information disclosure, they may make an unauthorized change in the fund use or illegally use the funds against the contract, which will may damage investors' interests greatly.

\section{The Risk Regulation of Equity Crowd Funding in China}

To improve relevant laws and regulations. In view of the risks faced by the equity crowd funding, the Securities Association of China published the Management Measures on Private Equity Crowd Funding Financing (Trial) (Exposure Drafts) on the website on December 18, 2014, which clearly stipulates that the equity crowd funding should take a non-public offering. At the same time, in order to accord with provisions of Article 10 of the Securities Law for non-public offering, the Management Measures claim that the investor must be a real-name registered user who meets the requirements of the Management Measures and who is verified by a specific equity crowd funding platform; second, the cumulative investors cannot exceed 200 people; third, the equity crowd funding platform can only recommend project information to real-name registered users. Moreover, whether the equity crowd funding platform or money raisers cannot publicize, promote or persuade the project to investors.

To avoid legal risks. Start-up enterprises with equity crowd funding as the shares can use the way of establishing a limited partnership to become a shareholder in the form of funds. After the financing is completed, the investors can form a limited partnership where the leaders are GP (General Partner, it refers to the Fund Managers) and the followers are LP (Limited Partner, it refers to investors). Then they can become the shareholder in the form of a limited partnership in the start-up companies. Equity crowd funding platforms should take into account of the replacing management and professional third-party equity management. On one hand, crowd funding platform can build a specialized financial management team to earn some revenues; on the other hand, if there is a professional third-party equity management company to bear relevant responsibilities on behalf of the platform, they can better protect the interests of many investors.

To establish an investor access mechanism. The crowd funding platform should cooperate with professional evaluation agencies. In terms of investor credit audit, it is necessary to clearly define the rules of income classification for ordinary investors. All investors will be divided according to the geographical area, so as to set different standards and make ratings. According to the income, the platform should distinguish projects which they can invest to maximize the protection of investors. Second, the audit can adopt the form audit. The use of form audit can reduce the auditing cost of the platform to a certain extent and improve the financing efficiency, but it cannot guarantee the safety of financing. Therefore, the platform should improve the standard of form audit for investors and make a substantive audit for the leader to ensure that the leaders are qualified investors with rich investment experience. Moreover, the platform can sign an agreement with these leaders to ensure that the leaders and investment projects have no substantive private contact. To this end, the crowd funding platform needs to assume a certain audit responsibility.

To set up a project access mechanism. In order to avoid malicious financing of bad business, the crowd funding platforms have audit responsibility for business projects and they should introduce offline negotiation model, which means that investors and entrepreneurs can reach a initial after they communicate with each other on the crowd funding platform and they 
can negotiate offline. Then, investors can get more details and the actual face to face contact will reduce the risk of fraud brought by the virtual space.

\section{Summary}

Equity crowd funding is an emerging Internet financial model, which solves the financing difficulties of small, medium and start-up enterprises which lack funds support to a certain extent. In view of the legal problems in its operation and the operational risk of the project, it is necessary to speed up the establishment and improvements of laws and regulations at the supervisor level, and regulate the operation of the equity crowd funding, so that there are laws for them to abide by; the crowd funding platforms should continuously improve and innovate the model of "leading investment+following investment". These platforms can explore more rigorous risk control model from the perspective of investors and project access, so as to ensure the healthy and orderly development of equity crowd funding and to promote the development of national financial industry innovation.

\section{Acknowledgements}

2015 Youth Fund Project of Wuhan Donghu University: A Study on the Development of Equity Crowd Funding under the Background of Public Entrepreneurship and Innovation.

Project Director: Xiuping Li.

\section{References}

[1] An Gaohong. The Risks and Improvements of Equity Crowd Funding Platforms in China [J]. Hebei Enterprises, 2017, (02): 60-61.

[2] Fang Jianghong. A Risk Analysis of Equity Crowd Funding- A Case Study of Dajiatou [J]. Contemporary Economics, 2016, (35): 14-15.

[3] Zhu Xiangjie. A Response to the Risk of Information Asymmetry in Equity Crowd Funding [J]. Finance and Economy, 2016, (06): 90-92.

[4] Liu Xiangbin, Jian Huan and Cai Mianxi. An Analysis of the Risk and Risk Prevention of Equity Crowd Funding [J]. Journal of Mudanjiang University, 2016, (03): 31-33.

[5] Wu Bei. An Analysis of Investors' Risk and Its Prevention in Equity Crowd Funding [J]. Journal of Wuhu Vocational Institute of Technology, 2016, (01): 56-59.

[6] Ma Xu. An Analysis of Risk Regulation of Equity Crowd Funding [J]. Co-operative Economy and Science, 2015, (16): 50-51.

[7] Lv Jinpeng. A Study on Legal Risks and Countermeasures of Equity Crowd Funding in China [J]. Legal System and Society, 2015, (19): 110-111. 